\title{
THE TREATMENT OF SYPHILIS WITH PENICILLIN
}

\author{
BY
}

\author{
G. L. M. McELLIGOTT
}

Shortly after Mahoney and his colleagues revealed that a high proportion of early syphilitics could probably be cured by 60 three-hourly injections of 20,000 units of penicillin, though I was then in uniform and anxious to get supplies for the treatment of my Royal Air Force patients, I remember thinking that this in-patient treatment would not be practicable for the patients attending my clinic at St. Mary's Hospital. I remembered how difficult it used to be to persuade civil patients to come into hospital, even when they were quite unfit to be up and about ; and now, back in civil life, it is obvious that all except the destitute or the completely independent patient will refuse to risk the possibility of the disease being discovered and of losing his or her job. For this reason I was delighted to hear of the work of Lloyd Jones and his Royal Naval colleagues, who showed that the maintenence of a constant penicillin blood level was not invariably a sine qua non of success and who achieved quite impressive early results with daily injections of large doses of penicillin dissolved in water. About 100 Royal Air Force patients with primary syphilis were treated with eight daily injections of 300,000 units of penicillin in water, and, as far as can be seen from an admittedly inadequate follow-up, results at nine months were in line with those following the 60-injection scheme. In Liverpool, Doctors Lourie and Ross and their colleagues have investigated further the possibilities of treating out patients with aqueous penicillin (p. 11).

The discovery that an undefined proportion of penicillin K (IV) is liable to be present in the commercial product has, I think, justified Colonel Harrison's decision, at the Ministry of Health in 1944 , to advise that penicillin be not used alone in the treatment of syphilis in civil clinics, though when pure crystalline penicillin G (II) is obtainable in a consistently reliable and easily handled slow release vehicle it may be justifiable so to treat sero-negative primary infections.

However much we may admire the work and the set-up of the Rapid Treatment Centres in the
United States, I think most of us will agree that in the present circumstances early syphilis here must be treated largely on an out-patient basis. As you are aware, it is now common practice in the clinics to give these patients eight to ten daily injections of 500,000 to 600,000 units of penicillin in a beeswax-oil suspension (total 4 to 5 mega units), together with one standard course of ten injections of neoarsphenamine and bismuth, the whole treatment lasting about ten weeks.

\section{Experience at St. Mary's Hospital}

At St. Mary's Hospital in addition to the penicillin we give twelve injections, at four-day intervals, never exceeding a single dose of 0.45 g. N.A.B. and $0.2 \mathrm{~g}$. of bismuth. Treatment is thus completed in forty-eight days. This dosage is well tolerated ; toxic effects have not been unduly frequent, the commonest being secondary fever and " ninth day" reactions. When these occur, treatment is always completed with bismuth only and no attempt at desensitization is made. Up to the present the default rate during treatment has been low. Indeed, it is I think probable that the shorter the period of treatment, especially if it is less than one month, the greater will be the default rate during the subsequent observation period. It has been our experience that short courses of what appears to the patient to be dramatically successful treatment often breed a spirit of what may be called " unhealthy optimism "; this is particularly noticeable in the case of gonorrhœa treated with penicillin, and it is all too common for patients to desert the clinic as soon as their symptoms are relieved.

It is my present practice not to begin penicillin treatment until ten days after treatment with arsenicals and bismuth has been started. I have found that if the two treatments are commenced simultaneously it is sometimes difficult to decide whether a rash on the ninth day can be attributed to the penicillin or the arsenic. 
Neo-arsphenamine versus Arsphenoxide

I do not intend to defend my continuing preference for neo-arsphenamine over arsphenoxide. A passing enthusiasm for the latter was damped by the second-rate results we obtained in the Royal Air Force in a small series of 47 airwomen with secondary syphilis; 12 of these patients relapsed within a year after a semi-intensive course of tri-weekly injections of arsphenoxide and weekly ones of bismuth, a total dosage of at least $20 \mathrm{mg}$. of arsphenoxide per kilo of body weight being given, as well as at least $1.6 \mathrm{~g}$. of bismuth. It is fair to add that 12 cases of primary syphilis did well after this treatment, and it is possible that the dosage given to the secondary cases was inadequate.

\section{Virtues of Bismuth}

Frum what Dr. Moore has told us and from my own experience to date, I feel that, while penicillin may yet oust the arsenicals from a large part of the therapeutic field, bismuth will continue to hold its own as a safe and efficient adjuvant agent. For many years now we have successfully treated early syphilis with two drugs, neo-arsphenamine, a powerful anti-spirochætal substance of which it was not necessary to maintain a constant blood level, and bismuth, which exerted a steady pressure on the spirochæte between the successive hammer blows from the arsenical. It may yet be that bismuth will play the same role to penicillin as it has now for many years done to the organic arsenicals. Eagle's animal experiments have been confirmed in human syphilis, and have shown how unreliable was semiintensive arsenotherapy without concurrent bismuth. I have heard it suggested that an agent such as bismuth, slowly absorbed from a more or less enduring depot, is more likely to postpone relapse rather than aid cure. This is a superficially attractive theory but it is not sufficiently supported by experience.

\section{Tissue Levels of Penicillin}

Since most of us believe that in this country the admission to hospital of early syphilitics for treatment is not practical, we are much concerned as to whether or not the maintenence of a constant penicillin blood level is necessary for the successful treatment of early syphilis. If a constant level is essential, surely it is tissue level and not blood level that really concerns us. Tissue level is bound to lag behind blood level, and it should not be too difficult, possibly with the help of our surgical colleagues, to find out for how long penicillin remains in adequate concentration in normal tissue after its injection in various vehicles. It has, of course, been shown to remain in wounds and in certain pathological fluids for considerable periods.

\section{Injection Media}

Injections of high concentrations of penicillin in arachis oil with 4.8 per cent. beeswax are not too easy to handle and it is rarely possible to extract the last half c.cm. from each vial. Consequently, the accumulated wastage of penicillin must be enormous, a wastage which at the present time the country can ill afford. If it can be established that daily injections in a less viscous medium or even in simple aqueous solution will give equally good results (even if slightly larger doses are necessary), a great advance will have been made. I would again emphasize that the average working man or woman can usually only attend once a day for treatment ; even injections at twelve-hourly intervals are nearly always out of the question if the treatment has to be continued for a week or more.

\section{Penicillin in Late or Latent Syphilis}

With regard to the place of penicillin in the treatment of late or latent syphilis, I think the time has now come when all but a few patients should have the benefit of this almost completely non-toxic substance. Because of its very powerful antispirochætal action it should rarely be used initially without an adequate period of premedication with bismuth, and I have yet to see any severe Herxheimer effects with these precautions. An exception to this rule can, I think, be made in the case of the young pregnant woman with negative findings on physical examination. In her case it is imperative that penicillin be given as soon as possible to ensure against her transmitting infection to her offspring.

Penicillin in late syphilis will at the present stage doubtless be given in addition to, rather than in substitution for, other forms of treatment, though I believe that it is well within the bounds of possibility that future experience may teach us that in many cases penicillin alone will be adequate "insurance treatment." We are still in the dark and likely to be so for some time about the question of dosage, the period of administration, and the necessity for repeated courses. 